DOI: 10.20472/IAC.2018.035.047

\author{
JÓZSEF VARGA \\ Kaposvár University, Faculty of Economics, Hungary
}

GÁBOR SÁRDI

Kaposvár University, Faculty of Economics, Hungary

TAMÁS KOVÁCS

University of Sopron Alexandre Lamfalussy Faculty of Economics, Hungary

\title{
COMMUNITY CURRENCY, LOCAL CURRENCY, NEGOTIABLE VOUCHER AND OTHERS: A THEORETICAL ATTEMPT TO CLASSIFY MONEY SUBSTITUTES INTO A SYSTEM
}

\begin{abstract}
:
In our study we tried to group money substitutes including complementary currencies known as "community currencies" in particular pursuing a new kind of approach. This objective was supported by the question whether there is a structuring principle according to which we can make groups of the different types of currencies and money substitutes in a structured manner. We have substantial and continuously developing literature of community currencies. However, as we know there are not many publications and studies about their classification. It is true that several authors and organizations have tried to make categories of currencies that exist besides legal currencies or that can be operated (e.g. Lietaer, Kennedy, Regiogelde. V Cooperation, Utterguggenberger Institution, Blanc, Bode, Boonstra and his colleagues, Greco, Mertignoni), but our opinion is that they are incomplete.

On the one hand the aspects of classification developed in literature do not put the criteria of the classification into the whole monetary system and the currency system, on the other hand the main goal of certain criteria was not to create a structured system but to classify and to categorise the unique trials of money substitutes on the basis of some criteria. In our study we try to fill the two gaps above placing the certain types of money substitutes into a single system and a conceptual scheme.
\end{abstract}

\section{Keywords:}

community currency, money substitutes, classification

JEL Classification: E40, E42, R51 